\title{
APPLICATIONS OF GENERALIZED TRIGONOMETRIC FUNCTIONS WITH TWO PARAMETERS II
}

\author{
SHINGO TAKEUCHI
}

Abstract. Generalized trigonometric functions (GTFs) are simple generalization of the classical trigonometric functions. GTFs are deeply related to the $p$-Laplacian, which is known as a typical nonlinear differential operator. Compared to GTFs with one parameter, there are few applications of GTFs with two parameters to differential equations. We will apply GTFs with two parameters to studies on the inviscid primitive equations of oceanic and atmospheric dynamics, new formulas of Gaussian hypergeometric functions, and the $L^{q}$-Lyapunov inequality for the one-dimensional $p$-Laplacian.

Mathematics subject classification (2010): 33E05, 34L40.

Keywords and phrases: Generalized trigonometric functions, $p$-Laplacian, inviscid primitive equations, Gaussian hypergeometric functions, Lyapunov inequality.

\section{REFERENCES}

[1] M. Abramowitz And I. A. STEgun, Handbook of mathematical functions with formulas, graphs, and mathematical tables, National Bureau of Standards Applied Mathematics Series, 55 For sale by the Superintendent of Documents, U.S. Government Printing Office, Washington, D.C. 1964.

[2] P. J. Bushell And D. E. Edmunds, Remarks on generalized trigonometric functions, Rocky Mountain J. Math. 42 (2012), no. 1, 25-57.

[3] A. Cañada, J. A. Montero And S. Villegas, Liapunov-type inequalities and Neumann boundary value problems at resonance, Math. Inequal. Appl. 8 (2005), no. 3, 459-475.

[4] A. CAÑAda AND S. VIlleggas, A variational approach to Lyapunov type inequalities. From ODEs to PDEs, With a foreword by Jean Mawhin, SpringerBriefs in Mathematics. Springer, Cham, 2015.

[5] C. CaO, S. Ibrahim, K. NaKanishi And E. S. Titi, Finite-time blowup for the inviscid primitive equations of oceanic and atmospheric dynamics, Comm. Math. Phys. 337 (2015), no. 2, 473-482.

[6] P. DRÁBEK AND R. MANÁSEVICH, On the closed solution to some nonhomogeneous eigenvalue problems with $p$-Laplacian, Differential Integral Equations 12 (1999), 773-788.

[7] Y. Egorov And V. Kondratiev, On spectral theory of elliptic operators, Operator Theory: Advances and Applications, 89. Birkhäuser Verlag, Basel, 1996.

[8] A. Elbert, A half-linear second order differential equation, Qualitative theory of differential equations, Vol. I, II (Szeged, 1979), pp. 153-180, Colloq. Math. Soc. Janos Bolyai, 30, North-Holland, Amsterdam-New York, 1981.

[9] http://functions.wolfram.com/07.23.03.2583.01. (Accessed 27 February 2019).

[10] http://functions.wolfram.com/07.23.03.2888.01. (Accessed 27 February 2019).

[11] L. C. Evans, Partial differential equations, Second edition. Graduate Studies in Mathematics, 19. American Mathematical Society, Providence, RI, 2010.

[12] H. KobAYASHI AND S. TAKEUCHI, Applications of generalized trigonometric functions with two parameters, Commun. Pure Appl. Anal. 18 no. 3 (2019), 1509-1521.

[13] F. W. J. Olver, D. W. LOZIER, R. F. Boisvert AND C. W. Clark, NIST handbook of mathematical functions, With 1 CD-ROM (Windows, Macintosh and UNIX). U.S. Department of Commerce, National Institute of Standards and Technology, Washington, DC; Cambridge University Press, Cambridge, 2010. 
[14] M. E. Payton, L. J. Young And J. H. Young, Bounds for the difference between median and mean of beta and negative binomial distributions, Metrika 36, no. 6, 347-354.

[15] J. P. PINASCO, Lyapunov-type inequalities. With applications to eigenvalue problems, SpringerBriefs in Mathematics. Springer, New York, 2013.

[16] S. TAKEUCHI, Generalized Jacobian elliptic functions and their application to bifurcation problems associated with p-Laplacian, J. Math. Anal. Appl. 385 (2012), no. 1, 24-35.

[17] S. TAKEUCHI, Multiple-angle formulas of generalized trigonometric functions with two parameters, J. Math. Anal. Appl. 444 no. 2 (2016), 1000-1014.

[18] G. Talenti, Best constant in Sobolev inequality, Ann. Mat. Pura Appl. (4) 110 (1976), 353-372. 